almost wholly to, the western and north-western portions of great storms and blizzards.

(2) That there seems to be a law of general distribution of the different forms, the columnar to one, the tabular and granular to others, with many varieties associated together in other portions of such great storms.

(3) That this distribution is, with few exceptions, constant, that is, the same in nearly all storms.

Sufficient data has not as yet been collected to demonstrate beyond all doubt the fact that this law applies to all forms of crystals and to all storms alike.

Passing on to the variation in form of those crystals deposited by local storms, as compared with those of general storms, we find that these are very marked, except during intense cold.

The local storm types and those precipitated from low, de. tached clouds usually consist of large, frail, branching, tabular forms, devoid of a solid tabular nucleus (see No. 10), or of heavy granular varieties, similar one to the other, each according to its class. On the other hand, those deposited by general storms are usually more diversified in form and more complex in structure, the snowfall often consisting of two or more varieties associated together. The larger and more perfect columnar prisms, columnar forms possessing tabular outgrowths at one or both ends (which we might call doublets), truncated triangular forms (see Nos. 2 and 3), and solid tabular forms, the latter often possessing wonderfully beautiful and complex interior designs (as in No. I), are common only to general storms. Branching tabular and granular forms are common to both general and local storms, but they ordinarily possess solid nuclei if deposited from a general storm (as in Nos. 4-7), whereas the nuclei are generally absent (as in No. Io) if the crystals originated in local storms. During zero weather the crystals of local storms approach much nearer in form to those of general storms, and we find solid tabular forms, branching tabular forms possessing solid hexagonal nuclei and sometimes doublets, among the snowfall. Often during the intense cold succeeding a blizzard the snowfall will consist wholly of very minute columnar and pyramidal forms, or of both columnar and minute frost-like tabular forms, falling apparently from low, detached nimbus or alto-nimbus clouds, or even from a sky free, or nearly so, of cloudas.

During relatively mild temperatures each cloud stratum, if alone, there being no other clouds either above or below them, commonly precipitates each its own peculiar type of crystals. Low detached nimbus clouds deposit large, frail, branching tabular forms, similar to No. Io ; intermediate clouds, smaller, branching tabular forms, possessing solid hexagonal nuclei; and the high cirro-stratus clouds, small compact columnar and tabular forms. The large cumulus clonds of spring and autumn usually shed large, heavy, pyramidal-shaped granular snow. These granular forms frequently, if not invariably, possess nuclei of branching, tabular forms, and are usually precipitated when the temperature is near or somewhat above the freezing point.

Of the photomicrographs which accompany this article all, with the exception of No. IO, are those common to and were deposited by great storms.

Of the other numbers of the series, No. 2 is very rare and unusual, containing as it does eleven triangular divisions within its outlines. Apparently the lines of greatest growth were reversed during one stage of the growth of this strange form, thus differing widely from No. 3, which has outlines somewhat similar. No. 4 possesses a very rare unique nuclear design which is very difficult to explain by any process of crystallisation of which we know. No. 5 (a souvenir of the great blizzard of March I2, 1888) is very symmetrical, as also is No. 6 , of February 15 , 1901. No. 7 is, in all but the unimportant outermost points, a marvel of complexity and perfect symmetry. No. 9 is also a marvellously beautiful and symmetrical example of snow architecture.

Passing to the causes governing the formation of the nucleus, whether it be columnar or tabular, the electrified state of the atmosphere, whether negative or positive, and perhaps, also, as suggested by Prof. Cleveland Abbe, the presence in greater or less amounts of various gases and vapours in the atmosphere, may all be controlling factors.

Although much has been already learned about these interesting phenomena, yet there still remains much more. Cooperation between many observers is essential to carry out this work successfully. Simultaneous observations of the forms and changes the crystals undergo from hour to hour duxing our great blizzards should be made by many skilled observers; stationed along a general line extending north and south. These observers must be familiar with the names and approximate heights of the various clouds. This study should include observations of the kind and approximate height and direction of drift of the various clouds, direction and force of the surface wind, temperature of the air, and amount of moisture at the earth's surface; also its electric condition, whether negative or positive, and the portion of the storm from which the crystals emanate.

It is also highly desirable that observations be made to ascertain why the perfect crystals are more common in the western portion of storms, and also why certain portions produce certain types.

Such a study, supplemented by investigations as to the causes of the formation of the two fundamental types of hoar-frost crystals, would doubtless lead to the discovery of very many of the mysteries surrounding the origin and history of the wondrously beautiful forms of snow.

\section{A NEW JOURNAL OF ANATOMY.}

THE first number of a new scientific magazine-The American Journal of Anatoniy (Baltimore, November 1901)-has been received and merits a descriptive notice because; as it has been "founded to collect into one place, and present in a worthy manner, the many researches" of American anatomists, it marks a new departure in scientific journalism, and while its pages are but 98 in number we are informed that future issues will be in quarterly parts of about 125 pages each. The interest with which British anatomists regard their branch of science as practised in America has during the last four to five years been heightened by the association, as joint editor of our own long-established Journal of Anatomy and Physiology, of Prof. G. S. Huntington of the Columbia University at Washington, who is one of the chief promoters of the new journal now under review. The reason of this enhanced interest lies in the fact that his connection with the English publication was marked by the appearance in its pages of a paper of a kind to which its readers were unaccustomed. It deals with a series of sections of an early human embryo, and while containing nothing that is new, surpasses all precedent in being illustrated by II plates of photomicrographic figures which do not portray a single fresh fact and can only be defined as useless. When, further, it is observed that the paper (by an English author) which immediately followed this in order of publication was similarly granted 12 plates, where 4 might well have sufficed, there is no wonder that there arose in the minds of the supporters of the journal a misgiving, lest the new association might perhaps lead to disaster. Let it be said, however, that American papers since received have been of a more normal kind.

This consideration lends interest to the circumstance that in the journal under review one of the five papers submitted monopolises 37 of the $98 \mathrm{pp}$. which make up the issue, as well as the whole of the 9 plates and 27 of the 42 text figures. It deals with a series of human embryos, as illustrating "The Development of the Limbs, Body-wall, and Back, in Man," and is a joint production by Drs. C. R. Barden and W. H. Lewis, of Baltimore. It is carefully written, and of the illustrations no praise can be too high. But we deplore the fact that, beyond the more exact determination of the actual period at which some of the important constituents of the developing nervous system and parts of the fore- and hind-limbs are first differentiated, there is nothing either recorded or delineated in it which is new. As a chapter for a text-book it would be well-nigh ideal; but in a journal devoted to records of research and new observations it is out of place and does but hamper the way.

We wish no disrespect to the authors, for if, as we assume, in providing the positively magnificent illustrations, they have but availed themselves of the condition set forth in the editorial advertisement, "that the cost of more expensive plates must be borne in part by the authors," we would rather tender them our hearty thanks. While, however, we would thus appraise their enterprise and artistic taste, we are still of opinion that, if our surmise is correct, both these and their enthusiasm have been misapplied ; for if we are to proceed on these lines, the danger, at present obvious enough in all departments of anatomical NO. I 680 , vOL. 65$]$ 
inquiry, of the science becoming buried in its own literature will be rendered unavoidable. Of the other papers which fill the remaining $61 \mathrm{pp}$. of the issue before us there are four. One by $\mathrm{Dr}$. Preston Kyes, of Chicago, on "The Intralobular Framework of the Human Spleen," contains little that is new, and is chiefly noteworthy for the introduction of a method. Then follows a paper entitled "Studies on the Neuroglia," by Dr. Carl Huber, of Michigan, which embodies a useful résumé of the conflicting results of the observations of previous investigators. The author has adopted the comparative method of inquiry, and has done good service in relation to technique; and among his chief results is the conclusion that certain of the neuroglia fibres are not simply processes of the cells, or, as von Kölliker believed, of a differentiated cell-plate, but that they are to be regarded as intercellular.

The fourth paper is welcome, as dealing, in an up-to-date manner, with the modern topic of "The Normal Histology of the Human Hæmolymph Glands." Its author, Dr. A. S. Warthin, also of Michigan, gives it as his opinion that our conceptions of lymphoidal tissues are greatly broadened by the study of these glands. He distinguishes between "spleenolymph" and "marrowlymph" glands, on a basis of structural and functional differentiation. He defines the latter as retroperitoneal, and in many observed cases most prominent when associated with pathological conditions. $\mathrm{He}$ admits the existence of transitional types of gland, and suggests that the ordinary lymphatic gland is the most highly developed, and that the spleen stands in similar relationship to it through the spleenolymph gland as does the lymphoid marrow through the marrowlymph gland. He further regards the red marrow as "the most primitive type of lymphoid structure."

The fifth and last paper is by Prof. C. S. Minot, of Harvard Medical School, who needs no introduction to English anatomists. It is "On the Morphology of the Pineal Region, based upon its Development in Acanthias," and is a very careful study, mainly of the paraphysis and velum. Six "fundamental morphological divisions" are recognised "in the median line of the diencephalic roof," and for some of these new terms are proposed. It is pointed out, on a delimitation of that which the author terms the "paraphysial arch," as distinct from the "post velar," that the posterior commissure belongs morphologically to the mid.brain. The paraphysis is regarded as in all probability a true gland, akin to the infundibular gland and the glandular epiphysis of birds ; and it is suggested that these are severally comparable to ductless glands, and that they "supply some substances which are useful to the nervous system."

The journal is well supported, and its get-up is deserving of the highest praise. Its collaborators include the names of more than sixty persons, most of whom are either leaders in human and comparative anatomy in the United States or otherwise well known, and its editorial board is composed of eight of their number who are sufficiently representative, On the whole, we would congratulate our friends upon their venture ; and if they will only see to it that, whenever possible, they rest content to work upon a basis of the bare record of facts hitherto unobserved, whereby they will not burden an already overcrowded literature, we can at least assure them of our sympathy and good wishes, if not our actual support.

\section{UNIVERSITY AND EDUCATIONAL} INTELLIGENCE.

LORD Strathcona, the Lord Rector of the University of Aberdeen, has sent a cheque for $25,000 l$. towards the Aberdeen University building scheme, the public having subscribed $30,000 l$. and thereby more than fulfilled the condition under which Lord Strathcona promised his gift.

THE Prince of Wales has consented to visit Manchester on March I2 to open the Whitworth Hall at the Owens College. At a meeting of the Court of Governors of the College on Tuesday, the following motion was passed:- "That the time has arrived when steps should be taken to secure that there should be, as originally proposed by the Owens College, an independent University in Manchester."

$1 \mathrm{HE}$ annual meeting of the Geographical Association will be held at the College of Preceptors on Wednesday, January 15. Mr. Douglas W. Freshfield, president of the Association, No. 1680 , VOL. 65$]$ will occupy the chair, and an address will be delivered by the Right Hon. James Bryce, M.P., on "The Importance of Geography in Education." Tickets may be had on application to the hon. sec., Dr. A. J. Herbertson, 9, Staverton Road, Oxford, or to the hon. treas., Mr. J. S. Masterman, St. Margaret's, Dorking.

THE system of teaching by correspondence is not one which has attained to very great favour in this country, except, perhaps, as a means of preparing for examinations, and it would be considered by most especially unsuitable for studying such preeminently practical professions as civil, mechanical and electrical engineering, mining, \&c. Yet it appears from an article in a recent number of the New York: Electrical Reviers that this system has a considerable vogue in America. The International Correspondence Schools, in spite of the fact that they were only inaugurated ten years ago, now number more than 350,000 students, amongst whom a large proportion are following courses in engineering, and it is not the only institution of the kind in the States. A decidedly valuable feature of the system in the case of the electrical courses is that students are supplied with sufficient apparatus to carry out most of the fundamental experiments. No doubt this method of teaching can be of great benefit to those who are actually employed in engineering works and are thus more or less conversant with the practical side of the subject, and in consequence can be of considerable help in raising the efficiency of the country, which must ultimately depend on the efficiency of its workers.

A PAPER on German Technical Schools by Prof. V. C. Alderson, Dean of the Armour Institute of Technology, published in the Chicago Inter Ocean, contains some points which serve to accentuate the account given in last week's notes (p. 2I3) of the little that is being done for higher technical education in Great Britain. Prof. Alderson describes briefly the Technical High Schools at Charlottenburg, Karlsruhe, Munich, Hanover, Darmstadt and other German cities, and compares the work carried on in them with that of the techni. cal schools in the United States and Great Britain. He points out as a lamentable fact that the provision for engineering edu. cation in London is totally inadequate. "In this great city of $6,000,000$ people barely 600 students a year are provided with engineering instruction of an advanced character. In this great metropolis, which contains more engineers of every class than any other city in the world, and where there is the greatest demand for their services, not only at home, but in foreign enterprises financed in London, the provision for their education is comparatively nothing. Any one of the German Technische Hochschulen which I have described, with far less reason for existence, has a larger equipment, is more expensive to main. tain, covers a broader field of work, and is better fitted to exert a powerful influence upon the profession and the industries than the best technical school in London. Not only are the few schools now in the field inadequate for the purpose, but many fields of engineering education are entirely bare. Absolutely no provision is made for teaching marine engineering, naval architecture, railway engineering, munici. pal engineering, or architecture. These are departments of the utmost consequence for the continued prosperity of London, yet she allows her young men to pick up their training in the old-fashioned way, and if she needs a really capable man she must import him from Germany, Switzerland or America. London has received no greater shock recently than to wake up and find that the equipment of the new 'twopenny tube,' as the Electric Railway is called, was almost entirely American. The error which Englishmen make in this whole field of technical education is a failure to recognise the difference between th. skilled workman and the professional engineer. She has been endeavouring to compete with the highly trained scientific experts of Germany and America by simply educating the hand, training artisans in the belief that she was making professional engineers. Not until England is dotted with large and flourish. ing schools like the Central Technical College of London, not until the English realise the necessity of training both the hand and the head, and not until she perceives the full value of highgrade engineering education will she be safe from the intrusion of German and American engineers who have had a thorough engineering training." This view from outside confirms that which can be seen when our educational structure is examined from within, and supplies a further reason for increased scientific training for leaders of industry. 